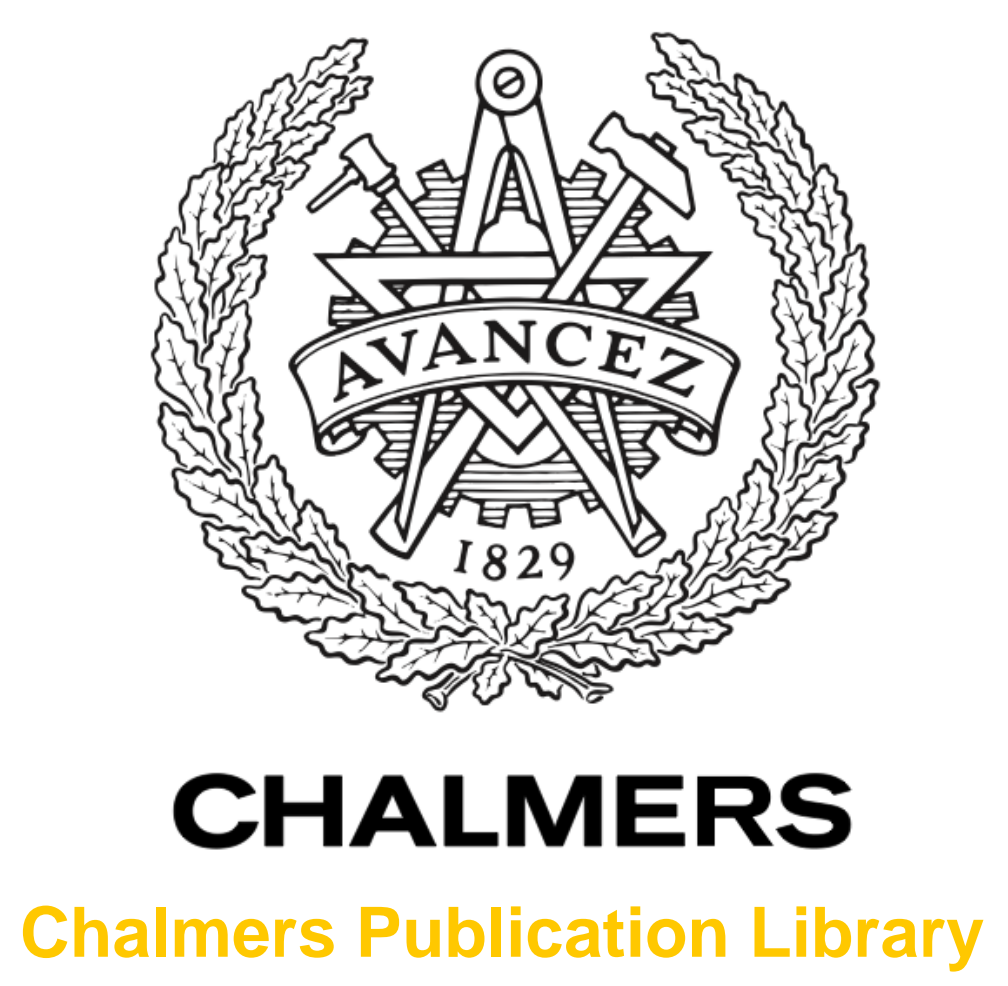

\title{
Design of 60GHz Planar Array Antennas Using PCB-based Microstrip-Ridge Gap Waveguide and SIW
}

This document has been downloaded from Chalmers Publication Library (CPL). It is the author's version of a work that was accepted for publication in:

\section{8th European Conference on Antennas and Propagation, EuCAP 2014, The Hague, The} Netherlands 6-11 April 2014

Citation for the published paper:

Razavi, S. ; Kildal, P. ; Xiang, L. (2014) "Design of 60GHz Planar Array Antennas Using PCB-based Microstrip-Ridge Gap Waveguide and SIW". 8th European Conference on Antennas and Propagation, EuCAP 2014, The Hague, The Netherlands 6-11 April 2014 pp. $1825-1828$.

http://dx.doi.org/10.1109/EuCAP.2014.6902150

Downloaded from: http://publications.lib.chalmers.se/publication/203778

Notice: Changes introduced as a result of publishing processes such as copy-editing and formatting may not be reflected in this document. For a definitive version of this work, please refer to the published source. Please note that access to the published version might require a subscription. 


\title{
Design of 60GHz Planar Array Antennas Using PCB- based Microstrip-Ridge Gap Waveguide and SIW
}

\author{
Seyed Ali Razavi ${ }^{1}$, Per-Simon Kildal ${ }^{2}$, Liangliang Xiang ${ }^{3}$, Haiguang Chen $^{4}$, Esperanza Alfonso ${ }^{5}$ \\ Electrical Engineering Department, Graduate University of Advanced Technology, Kerman, Iran, alirazavi_parizi@yahoo.com \\ ${ }^{2}$ Signals and Systems Department, Chalmers University of Technology, Göteborg, Sweden, per-simon.kildal@chalmers.se \\ ${ }^{3}$ Huawei, Shanghai, China. \\ ${ }^{4}$ Huawei Technologies Sweden AB, Gothenburg, Sweden. \\ ${ }^{5}$ Gapwaves AB, Gothenburg, Sweden.
}

\begin{abstract}
A wideband $2 \times 2$-slot element for a $60 \mathrm{GHz}$ antenna array is designed by making use of two double-sided printed circuit boards (PCBs). The upper PCB contains the four radiating cavity-backed slots backed by a substrate-integrated waveguide (SIW) cavity. The SIW cavity is excited by a coupling slot fed by a microstrip-ridge gap waveguide formed in the air gap between the upper and lower PCBs. The designed $2 \times 2$-slot element is considered in an infinite array environment. A sample $32 \times 32$ slot array aperture is simulated using infinite array approach and the relative bandwidth of $16 \%$ over $57-66 \mathrm{GHz}$ frequency range with the directivity of more than $38 \mathrm{dBi}$ over the operating bandwidth is obtained. The simulations are verified by measurements on a smaller $4 \times 4$ slot array surrounded by dummy elements.
\end{abstract}

Index Terms - gap waveguide, slot antenna array, soft and hard surfaces, EBG surface, substrate integrated waveguide (SIW).

\section{INTRODUCTION}

Slot array antennas are an interesting type of antennas that has been widely used in radar and communication applications at which high gain and narrow radiation patterns are required. By using hollow waveguide corporate distribution network, high radiation efficiency can be achieved since the transmission loss is very low [1-5].

The corporate distribution networks in [2-3] are single layer rectangular waveguide structures and the bandwidth of at most $9.5 \%$ is achieved. By a multi-layer distribution network it is possible to provide wider bandwidth, but cost and complexity increase. In [4-5] slot array antennas with a doublelayer distribution network are proposed, providing the bandwidth of $12-15 \%$ and efficiency of around $80 \%$.

In all the structures presented in [1-5], the great challenge is the cost and difficulty of antenna fabrication, in particular at high frequencies. Then, it becomes difficult to achieve good conductive contact between the metal parts used to realize the hollow waveguide structure.

The gap waveguide technology was introduced in 2009 as an alternative to hollow waveguides and microstrip lines at high frequencies with performance close to that of rectangular waveguides if the dimensions are properly chosen [6-7]. The gap waveguides are realized between two parallel flat metal surfaces, one of them with a texture, and there is no need to electrical contact between them. This represents a manufacturing advantage for multi-layer structures in particular at millimeter waves.

The gap waveguides exist in different forms depending on the topology of the textured surfacce [8]; ridge gap waveguides, groove gap waveguides, and microstrip gap waveguides. The textured surface contains also quasi-periodic elements that confine the waves inside the gap to the desired ridges, grooves and microstrip lines. The quasi-periodic elements have normally the form of metal pins, but they can also be mushrooms in PCBs, or simply metalized via holes like in the present paper. The ridge gap waveguide was experimentally demonstrated in [9], the inverted microstrip gap waveguide in [10], and the microstrip-ridge gap waveguide with mushrooms in [11] The gap waveguides can also be used to package microstrip circuits [12] and MMICs [13], The low loss characteristics are proven by the high-Q groove gap waveguide filter in [14].

The antenna in the present paper makes use of two parallel PCBs with no requirement to conductive contact between them. This two-PCB solution has become possible by combining ridge gap waveguide and SIW technologies. The two PCBs are separated by a small air gap. The gap waveguide ridges are realized by microstrip lines with grounded via-holes,

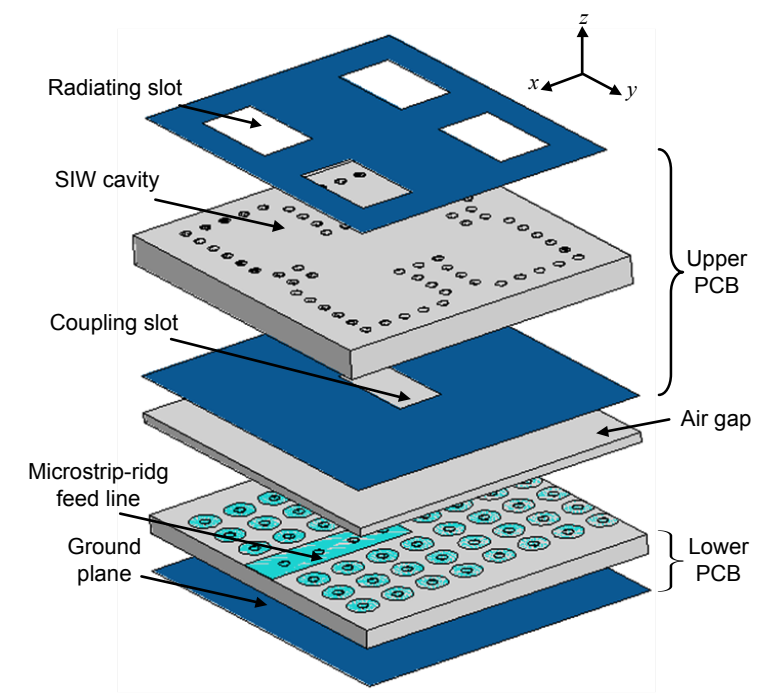

Fig. 1. Distributed 3-D view of $2 \times 2$-slot subarray. 
and the gap waveguide pins are realized by metallized viaholes with a pad on top distributed on both sides of the microstrip-ridge line as shown in the lower PCB in Fig. 1.

The present paper presents the numerical design of a $2 \times 2$ slot subarray for operation between 57 and $66 \mathrm{GHz}(16 \%)$ and for use in a large $32 \times 32$ slot array. The backed cavity of the $2 \times 2$-slot element is implemented using substrate integrated waveguide (SIW) technology, and the distribution network is implemented in the airgap between the upper and lower PCBs using microstrip-ridge gap waveguide technology.

\section{ANTENNA CONFIGURATION}

The $2 \times 2$-slot subarray is shown in distributed $3-\mathrm{D}$ view in Fig. 1, which clearly illustrates the two double-sided PCBs. Four radiating slots are backed by an SIW cavity, and the distribution network is formed by the microstrip-ridge gap waveguide between the upper and lower PCBs. The coupling between the upper PCB and the feed network is provided by a coupling slot. The $2 \times 2$-slot subarrays are separated by SIW corrugations in E-plane direction. In Fig. 2 we have shown a sample $4 \times 4$ slot array only to illustrate how the SIW corrugations are integrated in the array topology. A single SIW corrugation is located between each subarray in E-plane and appears as a dielectric-filled longitudinal cavity under a long slot and with via hole walls, filling the space between neighboring subarrays in E-plane only. This works as a soft surface to reduce sidelobes due to the wide radiation patterns of the slot subarrays in E-plane and in particular at $90^{\circ}$. The

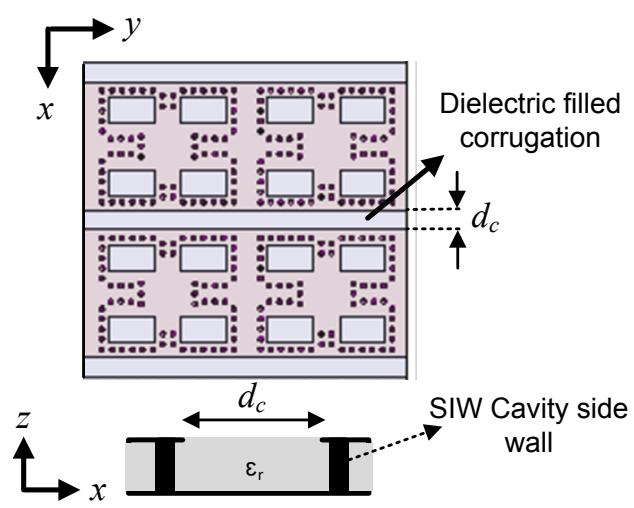

Fig. 2. SIW corrugation between $2 \times 2$-slot subarrays.

slot subarrays patterns are much better in H-plane, so there is no need for corrugations in H-plane. The SIW corrugations also reduce mutual coupling between subarrays. The reduced mutual coupling between subarrays made it easier to impedance match the subarrays in the infinite array environment. The radiating slots are uniformly spaced in both $x$ and $y$ directions with distances smaller than, but close to, one wavelength, in order to both minimize the grating lobe level and get the highest possible directivity of a large $32 \times 32$ slot array.

In the design of the $2 \times 2$-slot subarray, we took the mutual coupling between subarrays into consideration by analyzing the $2 \times 2$-slot subarray in an infinite two-dimensional array.

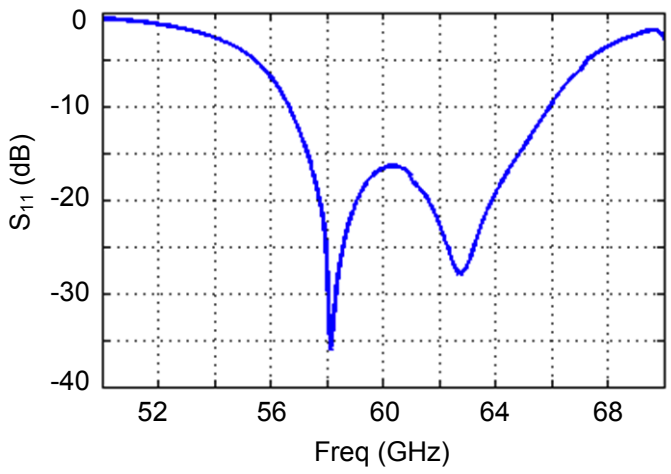

Fig. 3. Reflection coefficient of designed $2 \times 2$-slot subarray with periodic walls.

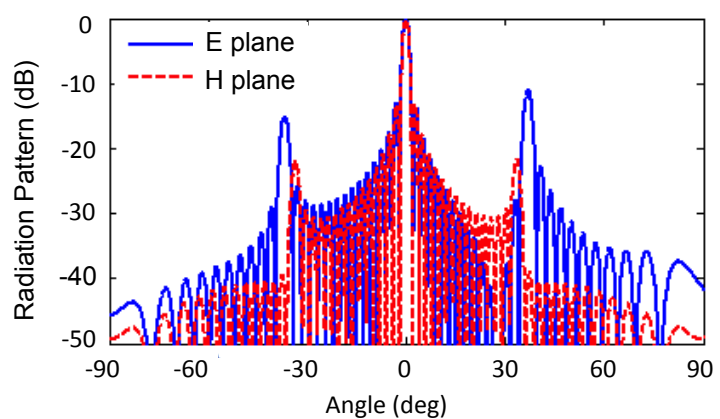

Fig. 4. Normalized radiation patterns of proposed structure with $32 \times 32$ slot array aperture $@, 61.5 \mathrm{GHz}$.

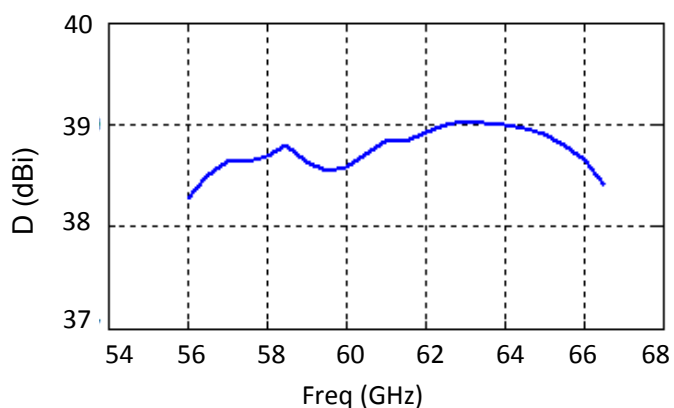

Fig. 5. Directivity of proposed structure with $32 \times 32$ slot array aperture over its operating bandwidth.

\section{SimUlation RESULTS}

The simulated reflection coefficient of the designed $2 \times 2$ slot subarray in an infinite array environment is shown in Fig. 3. We observe that $\mathrm{S}_{11}$ is lower than $-10 \mathrm{~dB}$ over the desired $16 \%$ frequency band. In Fig. 4 , the E-\& H-plane radiation patterns of the large $32 \times 32$ slot array is shown at $61.5 \mathrm{GHz}$ (the center of operating bandwidth). As expected, the grating lobe level in E-plane is higher than that in H-plane, but in both planes the grating lobe level is acceptable for the considered application. It is observed that in E-\& H-planes the grating lobe level is below $-10 \mathrm{~dB}$ and $-20 \mathrm{~dB}$ respectively.

In Fig. 5 the directivity of the $32 \times 32$ slot array aperture is illustrated versus frequency. The largest directivity value is 39 $\mathrm{dB}$ and minimum value over the band is $0.7 \mathrm{~dB}$ lower. 


\section{VALIDATION ON 4×4 SLOT ARRAY WITH SURROUNDING DUMMY SLOTS}

We decided to build a small array consisting of $4 \times 4$ slots, i.e. a $2 \times 2$ array of $2 \times 2$-slot subarrays. This array is too small to verify the design approach regarding the element spacing and grating lobe suppressions. However, it is large enough to validate if we have good control of the radiation characteristics using HFSS, and the effect of the SIW corrugations. The distribution network is fully branched as shown in Fig. 6, feeding the 4 subarrays with equal amplitude and phase. It is realized in microstrip-ridge gap waveguide with a $90^{\circ}$ transition to WR15 rectangular waveguide fixed to the back side of the lower PCB. The feed network is optimized in order to have minimum return loss over the operating bandwidth.

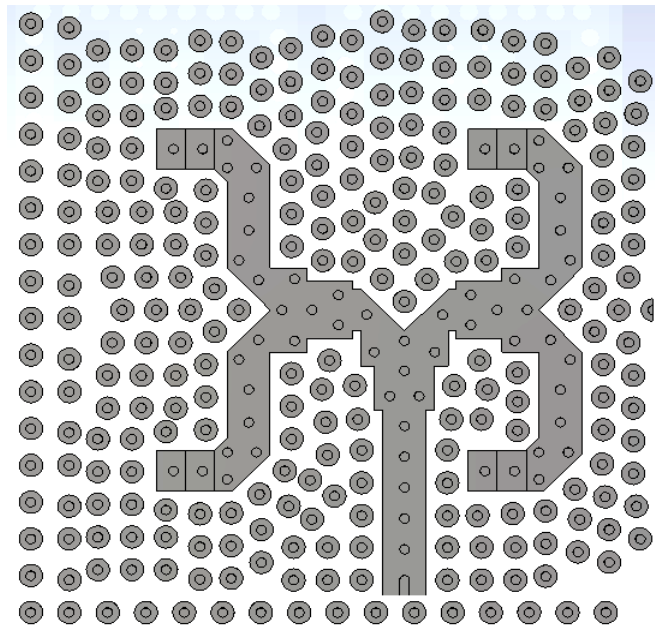

Fig. 6. Designed corporate feed network for $4 \times 4$ slot array antenna.

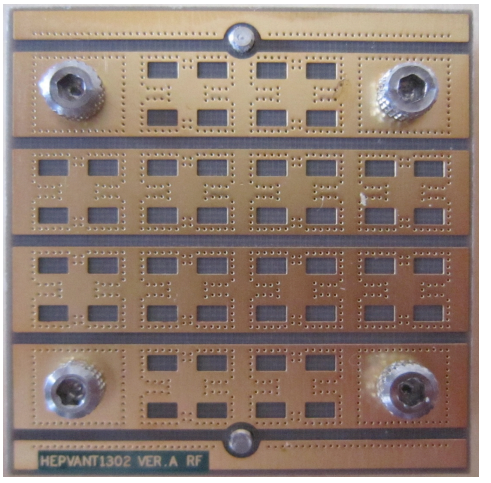

Fig. 7. Fabricated antenna. A $4 \times 4$ slot array surrounded by some dummy slots.

The constructed validation antenna is shown in Fig. 7. The centered $4 \times 4$ slot array is excited by the corporate feed network and the other surrounding slots are dummy elements. In Fig. 8 the measured reflection coefficient of the full $4 \times 4$ slot array with dummy slots is compared with simulations full wave simulations, and with simulations of the $2 \times 2$-slot subarray in an infinite array environment. We see good agreement between results of full wave simulation, infinite array approach and measurement. . The full wave simulation result shows good impedance matching $\left(\mathrm{S}_{11} \leq-10 \mathrm{~dB}\right)$ within the frequency range of $56.37-65.43 \mathrm{GHz}(16 \%)$ which is close to the result obtained by infinite array approach. The measured $\mathrm{S}_{11}$ is matched better than $-10 \mathrm{~dB}$ between $55.7 \mathrm{GHz}$ and $65.2 \mathrm{GHz}(17 \%)$.

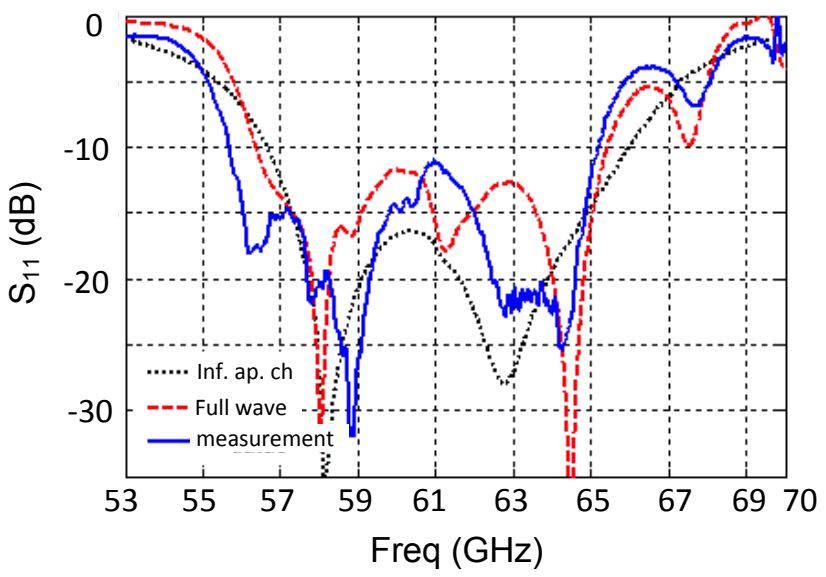

Fig. 8. Reflection coefficient of $4 \times 4$ slot array antenna. Solid line and dashed line are $\mathrm{s}_{11}$ of $4 \times 4$ slot array obtained by measurement and full wave simulation respectively. Dotted line is $s_{11}$ for a $2 \times 2$ slot subarray in infinite array.
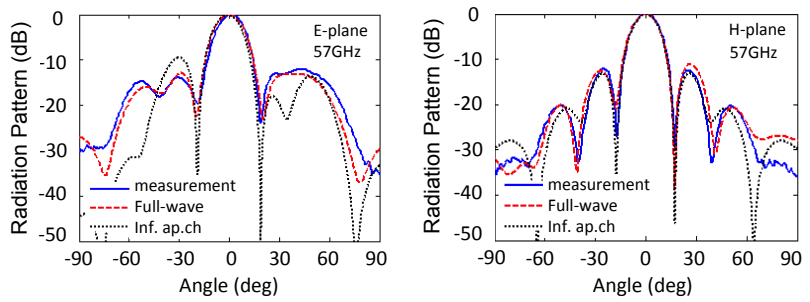

(a)
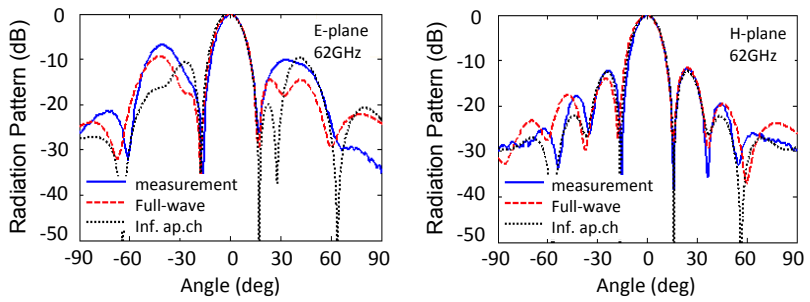

(b)
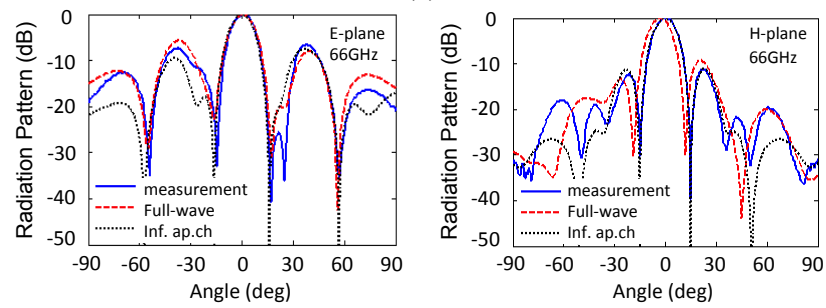

(c)

Fig. 9. Radiation patterns of $4 \times 4$ slot array antenna in E- and H-planes @ (a). $57 \mathrm{GHz}$ (b). $62 \mathrm{GHz}$ and (c). $66 \mathrm{GHz}$. In each plot the results of full wave simulation and measurement of $4 \times 4$ slot array is compared with that obtained by infinite array approach on $2 \times 2$ slot subarray.

The simulated and measured E- and H-plane radiation patterns of the designed $4 \times 4$ slot array antenna are shown in Fig. 9 at three frequencies over its operating bandwidth. The 
simulations include also here the full-wave approach including dummy slots, and an infinite array approach using the $2 \times 2$ subarray as the element. We decided to measure the radiation patterns at exactly the same frequencies as we did the simulations, in order to validate the results obtained by the full wave and infinite array approaches. We can finally observe quite good agreement between the results obtained by full wave simulations, infinite array approach, and measurements. In Fig. 9 we can see that for the frequencies of $62 \mathrm{GHz}$ and $66 \mathrm{GHz}$, the grating lobe level is higher than $-10 \mathrm{~dB}$. This is due to the small size of the validation antenna ( $4 \times 4$ slots only). For a big array (eg. $32 \times 32$ slot array), the grating lobe level will become lower than $-10 \mathrm{~dB}$ as illustrated in Fig. 4 which is simulated by the same infinite array approach that showed high sidelobes for a $4 \times 4$ slot array in Fig. 9.

\section{CONCLUSION}

We have numerically designed a wideband planar slot array antenna at $60 \mathrm{GHz}$ using microstrip-ridge gap waveguide and SIW technologies. The two-PCB technology combined with wide bandwidth and good radiation patterns make the proposed structure attractive for practical $60 \mathrm{GHz}$ applications. A sample $4 \times 4$ slot array antenna was fabricated to verify the design approach regarding the element spacing and grating lobe suppressions and to validate if we have good control of the radiation characteristics and the effect of SIW corrugations. Good agreement between measured and simulated results were finally obtained...

\section{REFERENCES}

[1] S. S. Oh, J. W. Lee, M. S. Song, and Y. S. Kim, "Two-layer slotted waveguide antenna array with broad reflection/gain bandwidth at millimetre-wave frequencies," IEE Proc.-Microw. Antennas Propag., vol. 51, no. 5, pp. 393-398, Oct. 2004.

[2] Y. Kimura, Y. Miura, T. Shirosaki, T. Taniguchi, Y. Kazama, J. Hirokawa, and M. Ando, "A low-cost and very compact wireless terminal integrated on the back of a waveguide planar array for $26 \mathrm{GHz}$ band fixed wireless access (FWA) systems," IEEE Trans. Antennas Propag., vol. 53, no. 8, pp. 2456-2463, Aug. 2005.
[3] S. Park, Y. Tsunemitsu, J. Hirokawa, and M. Ando, "Center feed single layer slotted waveguide array," IEEE Trans. Antennas Propag., vol. 54, no. 5, pp. 1474-1480, May 2006.

[4] K. Jung, H. Lee, G. Kang, S. Han, and B. Lee, "Cavity-backed planar slot array antenna with a single waveguide-fed subarray," in Proc. IEEE Antennas Propag. Soc. Int. Symp., 115.5, Jun. 2004.

[5] Y. Miura, J. Hirokawa, M. Ando, Y. Shibuya and G. Yoshida, "Doublelayer full -corporate-feed hollow-waveguide slot array antenna in the 60 GHz band," IEEE Trans. Antennas Propag., vol. 59, no. 8, pp. 2844 2851, Aug 2011.

[6] P. S. Kildal, E. Alfonso, A. Valero-Nogueira, and E. Rajo-Iglesias, "Local metamaterial-based waveguides in gaps between parallel meta plates," IEEE Antennas and Wireless Propagation Letters, vol. 8, pp. 84-87, 2009.

[7] P. S. Kildal, "Waveguides and transmission lines in gaps between parallel conducting surfaces," European patent application No. PCT/EP2009/057743, 2009.

[8] P. S. Kildal, "Three metamaterial-based gap waveguides between parallel metal plates for $\mathrm{mm} / \mathrm{submm}$ waves," in 3rd European Conference on Antennas and Propagation (EuCAP 2009), pp. 28-32.

[9] P. S. Kildal, A. U. Zaman, E. Rajo-Iglesias, E. Alfonso, and A. ValeroNogueira, "Design and experimental verification of ridge gap waveguide in bed of nails for parallel-plate mode suppression," IET Microwaves, Antennas and Propagation, vol. 5, no. 3, pp. 262-270, 2011.

[10] A. Valero-Nogueira, M. Baquero, J. I. Herranz, J. Domenech, E. Alfonso, and A. Vila, "Gap waveguides using a suspended strip on a bed of nails," IEEE Antennas and Wireless Propagation Letters, vol. 10, pp. 1006-1009, 2011.

[11] E. Pucci, E. Rajo-Iglesias, P.-S. Kildal, "New Microstrip Gap Waveguide on Mushroom-Type EBG for Packaging of Microwave Components", IEEE Microwave and Wireless Components Letters, Vol. 22, No. 3, pp. 129-131, March 2012.

[12] E. Rajo-Iglesias, A. Uz Zaman, P.-S. Kildal, "Parallel plate cavity mode suppression in microstrip circuit packages using a lid of nails", IEEE Microwave and Wireless Components Letters, Vol. 20, No. 1, pp. 3133, Dec. 2009

[13] A.U. Zaman, T. Vukusic, M. Alexanderson, P.-S. Kildal, "Gap Waveguide PMC Packaging for Improved Isolation of Circuit Components in High Frequency Microwave Modules", accepted for publication in IEEE Transactions on Components, Packaging and Manufacturing Technology, July 2013

[14] A. U. Zaman, A. Kishk, and P.-S. Kildal, "Narrow-band microwave filter using high Q groove gap waveguide resonators without sidewalls", IEEE Transactions on Components, Packaging and Manufacturing Technology, Vol. 2, No. 11, pp. 1882-1889, November 2012. 